\title{
Are a Speculum Examination and Wet Mount Always Necessary for Patients With Vaginal Symptoms? A Pilot Randomized Controlled Trial
}

\author{
Matthew Anderson, MD, MSc, Andreas Cobrssen, MD, Kathleen Klink, MD, and \\ Danit Brabver, BS
}

Purpose: The suggested evaluation of vaginal symptoms is based on the wet mount diagnosis of candidiasis, trichomoniasis, and bacterial vaginosis. We wondered if patients with vaginal symptoms could be managed initially based solely on symptoms.

Methods: This pilot randomized controlled trial was conducted in 2 urban family practice clinics and enrolled 46 premenopausal, nonpregnant women with acute vaginal symptoms. In the control arm, women were managed based on a speculum examination and wet mount. In the intervention arm, women were managed based on symptoms. Women were tested for gonorrhea, chlamydia, and trichomoniasis and called 2 weeks later to assess symptom resolution, adverse medication effects, need for revisit, and satisfaction with care.

Results: Forty-one of 44 women (93\%) felt better 2 weeks after the visit; 28 (64\%) had complete resolution of symptoms. The intervention arm had slightly better resolution of symptoms $(P=.046)$; there were other no differences between the 2 arms. Three women were diagnosed with sexually transmitted diseases (trichomoniasis, chlamydia, and gonorrhea).

Conclusions: Our pilot study suggests that in selected women it may be reasonable to initially manage vaginal complaints based on symptoms. These results should be confirmed in other larger trials. Testing for sexually transmitted diseases is important in our population. ( $\mathrm{J}$ Am Board Fam Med 2009; 22:617-624.)

Vaginal symptoms are extremely common in women presenting to primary care settings and are considered among the most common reasons women consult with physicians. ${ }^{1,2}$ The current standard of care for vaginal symptoms focuses on diagnosing bacterial vaginosis, trichomoniasis, and vaginal candidiasis us-

This article was externally peer reviewed.

Submitted 10 January 2009; revised 14 April 2009; accepted 22 April 2009.

From the Department of Family and Social Medicine, Montefiore Medical Center and Albert Einstein College of Medicine, Bronx, NY (MA); the Department of Urban Family Practice, Beth Israel Medical Center (AC, DB); and the Center for Family and Community Medicine, Columbia University (KK), New York, NY.

Funding: This project was supported by the Agency for Healthcare Research and Quality (AHRQ) grant no. 1R03HS016050-01.

Conflict of interest: none declared.

Corresponding author: Matthew Anderson, MD, MSc, Residency Program in Social Medicine, 3544 Jerome Ave., Bronx, NY 10467 (E-mail: Bronxdoc@gmail.com).

\footnotetext{
See Related Commentary on Page 602.
}

ing evaluation of the discharge with microscopy, $\mathrm{pH}$ testing, and the whiff test. ${ }^{3-5}$ Although theoretically it makes sense to diagnose before treatment, the actual benefit of following this approach has not been demonstrated in a clinical trial.

There are both theoretical and practical problems with an approach to vaginal symptoms that focuses on identifying bacterial vaginosis, trichomoniasis, and candidiasis. First, the differential diagnosis of vaginal complaints is broad, including not only other microbial causes (herpes simplex, cervicitis, urinary tract infection) but also dermatologic conditions (desquamative inflammatory vaginitis, lichen simplex); vulvodynia; and concerns about sexual dysfunction and abuse. Secondly, studies in a wide variety of clinical settings show that no cause is identified in $25 \%$ to $50 \%$ of women with vaginal symptoms. ${ }^{6-8}$ This suggests that at least some women may present because of excessive physiologic discharge. Further complicating the picture, candida and trichomonas are often isolated from asymptomatic women, ${ }^{9,10}$ so it is difficult to distinguish symptomatic infection from mere colo- 
nization of the vagina. Finally, to diagnose candidiasis, trichomoniasis, and bacterial vaginosis, a speculum examination and an evaluation of discharge using $\mathrm{pH}$, the whiff test, and microscopy are required. These tests are not all that accurate. ${ }^{11}$ They are timeconsuming, they require Clinical Laboratory Improvement Amendments certification, and speculum examination may be uncomfortable for the patient.

In clinical practice many practitioners do not seem to follow the recommended approach. ${ }^{12} \mathrm{~A}$ retrospective study of women seen in a vaginitis specialty clinic found that the referring physician had performed a microscopic evaluation of the vaginal fluid in only $63 \%$ of cases, whereas measurement of vaginal $\mathrm{pH}$ and the whiff test were documented only $3 \%$ of the time. ${ }^{13}$ Even when these exams are performed, physician and nurse practitioner diagnoses show poor correlation with culture results. ${ }^{14}$

A randomized trial in Thailand of 240 women with symptomatic vaginal discharge demonstrated no clinically important differences between an algorithm based on diagnosing pathogens and an algorithm based solely on physical examination findings. ${ }^{15}$ A retrospective study in Washington found that management based on risk factors and symptoms offered symptomatic relief and prevention of transmission of trichomonas. Little additional benefit resulted from a speculum examination and microscopy. ${ }^{16}$ Dissatisfaction with current practice has led some in the field to suggest alternative algorithms. ${ }^{17}$

We were interested in studying the role of the speculum examination and wet mount in the evaluation of vaginal complaints. To do this we used a randomized controlled design to compare symptom resolution in patients treated based on wet mount findings with treatment based solely on symptoms. We also wanted to evaluate the role of sexually transmitted diseases (STDs) in our population to inform any "no examination" protocol.

\section{Methods \\ Study Setting}

This study was conducted at 2 family practice ambulatory clinics. The Family Health Center is a federally funded community health center and part of the Montefiore Medical Center outpatient network caring for underserved populations in the Bronx, New York. Phillips Family Practice Center is part of the Beth Israel Medical Center and is run by the Institute for Family Health. Both sites have family medicine residents in training.

\section{Study Population}

Any premenopausal, nonpregnant woman older than 21 and presenting with a chief complaint of vaginal itch, malodor, discharge, pain, or irritation was considered eligible for the trial. We excluded women younger than 21 because of the increased risk of pelvic inflammatory disease in this group. We accepted a patient self-report of premenopausal status. To avoid including women with atrophic vaginitis we excluded women older than 45 who had undergone a hysterectomy. Pregnant patients were excluded based on a urine human chorionic gonadotropin test done at the time of presentation or a statement by the patient that she was pregnant. Patients with fever, lower abdominal pain, or significant bleeding were excluded. Patients who had taken over-the-counter medication for vaginal symptoms were not excluded from the study. Those who had used prescribed medications for vaginal complaints within 3 weeks of enrollment were excluded.

\section{Enrollment, Consent, Randomization, Incentives}

Eligible patients were identified by either clinic administrative, nursing, or professional staff and were referred to one of the primary investigators (MA, AC) or a research assistant. The study was briefly described and the patient's suitability for the study was ascertained. Interested patients were given a full explanation of the study and completed an informed consent.

After giving consent, the patient was seen by a provider who did the initial clinical interview using a standardized data collection form. The clinician was provided with one sealed, opaque envelope and when the interview was completed the envelope with the patient's assignment group was opened. These envelopes had been prepared previously by a research assistant not involved the study. She used a random number calculator assigning odd numbers to the intervention group and even numbers to the control group.

Patients who completed the initial office visit were given a \$20 reimbursement for their time. Those who completed the follow-up phone interview received a second \$20 reimbursement. All patients had access to a voicemail (checked daily) in case they developed problems after their enrollment. 
Table 1. Management Algorithm and Treatments for Vaginal Symptoms

\begin{tabular}{|c|c|c|}
\hline Control Group & Intervention Group & Treatments \\
\hline $\begin{array}{l}\text { Patient meets } 3 \text { or } 4 \text { Amsel criteria and } \\
\text { is diagnosed with bacterial vaginosis }\end{array}$ & $\begin{array}{l}\text { Patients whose chief complaint is odor } \\
\text { are diagnosed with presumptive } \\
\text { bacterial vaginosis }\end{array}$ & $\begin{array}{l}\text { Metronidazole } 500 \mathrm{mg} \text { bid for } 7 \text { days } \\
\text { Alternative: Clindamycin } 2 \% \text { cream } \\
\text { intravaginal bid for } 7 \text { days or Metrogel } \\
\text { intravaginal qhs for } 5 \text { days }\end{array}$ \\
\hline $\begin{array}{l}\text { Yeast forms are seen and patient is } \\
\text { diagnosed with candidiasis }\end{array}$ & $\begin{array}{l}\text { Patients whose chief complaint is } \\
\text { itching or irritation are diagnosed } \\
\text { with presumptive candidiasis }\end{array}$ & $\begin{array}{l}\text { Fluconazole } 150 \mathrm{mg} \text { po once at the time of } \\
\text { visit } \\
\text { Alternative: Terconazole vaginal cream } \\
\text { or suppositories }\end{array}$ \\
\hline $\begin{array}{l}\text { Trichomonads are seen on microscopy } \\
\text { or Trichomonas vaginalis culture is } \\
\text { positive }\end{array}$ & Patients treated if culture is positive & $\begin{array}{l}\text { Metronidazole } 2 \mathrm{~g} \text { po at the time of visit; } \\
\text { partner referred for treatment } \\
\text { Alternative: Metronidazole } 500 \mathrm{mg} \text { po } \\
\text { bid for } 5 \text { days }\end{array}$ \\
\hline $\begin{array}{l}\text { If none of the above, provider may } \\
\text { either treat as per the intervention } \\
\text { arm or not treat }\end{array}$ & $\begin{array}{l}\text { All other patients are treated for both } \\
\text { presumptive candidiasis and } \\
\text { presumptive bacterial vaginosis }\end{array}$ & \\
\hline
\end{tabular}

\section{Intervention}

Patients were randomized into one of 2 arms (Table 1). Women assigned to the control arm underwent a speculum examination, a measurement of vaginal $\mathrm{pH}$, and microscopic examination of any vaginal discharge. Management was based on the results of these tests. Patients were managed based on their symptoms if the tests were inconclusive. Women in the intervention arm were managed based solely on their symptoms and not based on an examination. Women in both groups had a vaginal swab for trichomonas culture collected by the clinician; a urine sample was taken for gonorrhea and chlamydia testing.

Attending physicians either performed or supervised all visits. All attending physicians perform pelvic examination and wet mounts as part of their routine clinical practice. To maximize patient compliance, study medications were dispensed to patients at the time of the visit. Use of single dose fluconazole and metronidazole (for trichomonas) was preferred.

\section{Measures}

At baseline the vaginal symptom score (VSS) was administered to all patients. The VSS is an unpublished 19-question survey focusing on symptoms, self-treatment, impact on social life, concerns about health and smell, and relationship difficulties; it is available in both Spanish and English. Data were collected by the clinician on basic demographic data, medical history, and use of other medications.

Approximately 2 weeks after enrollment the patients were contacted by phone for follow-up.
Women were asked at that time if their symptoms were worse, unchanged, somewhat better, or completely resolved; this was the main clinical outcome of the study. The VSS was again administered and women were asked 4 questions about adverse reactions to medication and 5 questions about satisfaction with the visit. This follow-up call was made by the same research assistant who enrolled patients at the Family Health Center (38 patients), but by a different research assistant for Phillips Family Practice Center patients (6 patients).

\section{Data Management and Analysis}

Data in this study were entered into an Access database (Microsoft Corp., Redmond, WA) using Epi-Info (Centers for Disease Control and Prevention, Washington, DC) and analyzed using Stata version 10.1 (StataCorp LP, College Station, TX). For comparison of outcomes $t$ tests or Fisher's exact tests were used. We analyzed the VSS using a hierarchical linear regression model with a random intercept at the individual level. Fixed effects in the model reflected baseline differences in randomization groups, change in score from initial to follow-up interview, and differences between changes in scores between the 2 arms.

\section{Etbics}

This study was approved by the Institutional Review Boards at Montefiore Medical Center and the Institute for Family Health. 
Table 2. Characteristics of the Study Population of Forty-six Women with Vaginal Symptoms

\begin{tabular}{|c|c|c|c|}
\hline & $\begin{array}{l}\text { All Women } \\
(\mathrm{n}=46)\end{array}$ & $\begin{array}{l}\text { Intervention Group } \\
\quad(\mathrm{n}=24)\end{array}$ & $\begin{array}{l}\text { Control Group } \\
\quad(\mathrm{n}=22)\end{array}$ \\
\hline Age (years) (mean [SD]) & $32(7.6)$ & $31.6(7.7)$ & $32.5(7.7)$ \\
\hline Range & $21-48$ & $(21-47)$ & $(22-48)$ \\
\hline Nulliparous (n [\%]) & $7(15)$ & $4(17)$ & $3(14)$ \\
\hline Gravity (mean $[\mathrm{SD}]$ ) & $3.3(2.6)$ & $3.3(2.0)$ & $3.4(3.2)$ \\
\hline Range & $1-15$ & $1-7$ & $1-15$ \\
\hline Sexually active (n [\%]) & $39(85)$ & $19(80)$ & $20(91)$ \\
\hline History of STD & $18(39)$ & $8(33)$ & $10(45)$ \\
\hline Current contraceptive use* (n [\%]) & $5(11)$ & $1(4)$ & $4(18)$ \\
\hline Current antibiotic usage (n [\%]) & $3(7)$ & $0(0)$ & $3(14)$ \\
\hline \multicolumn{4}{|l|}{ Study site (n) } \\
\hline FHC & 40 & 20 & 20 \\
\hline Phillips & 6 & 4 & 2 \\
\hline \multicolumn{4}{|l|}{ Chief complaint } \\
\hline Itching (n [\%]) & $16(35)$ & $9(38)$ & $7(32)$ \\
\hline Odor (n [\%]) & $16(35)$ & $8(33)$ & $8(37)$ \\
\hline Discharge(n [\%]) & $9(20)$ & $3(13)$ & $6(27)$ \\
\hline Irritation (n [\%]) & $3(7)$ & $2(8)$ & $1(5)$ \\
\hline Other (n [\%]) & $2(4)$ & $2(8)$ & $0(0)$ \\
\hline Self therapy ${ }^{\dagger}(\mathrm{n}[\%])$ & $14(30)$ & $7(29)$ & $7(32)$ \\
\hline Clotrimazole & & 1 & 0 \\
\hline Douche & & 2 & 0 \\
\hline Tioconazole & & 3 & 4 \\
\hline Vagisil & & 3 & 3 \\
\hline Zinc oxide & & 0 & 1 \\
\hline Wipees & & 1 & 0 \\
\hline Homeopathy & & 0 & 1 \\
\hline
\end{tabular}

*The woman in the intervention group used oral contraceptive pills. Two women in the control group used oral contraceptive pills and 2 used Depo-Provera.

${ }^{\dagger}$ Some women took more than one therapy. Specific types of self-therapy shown as $\mathrm{n}$.

STD, sexually transmitted disease; FHC, family health center.

\section{Results}

\section{Study Population and Clinical Presentation}

From January 2007 to June 2008 we enrolled a total of 46 women; 40 were from the Family Health Center. The average age of these patients was 32.0 years (range, 21-48 years; SD, 7.6 years). Thirty-nine $(85 \%)$ of the women had been pregnant with a mean parity of 3.3 pregnancies (range, $1-15$ pregnancies; SD, 2.6 pregnancies; median, 3 pregnancies). Thirtynine $(85 \%)$ of the women reported that they were sexually active. Eighteen (39\%) reported a history of a STD. Six women reported a history of asthma, 3 reported past sinusitis/allergies, 2 reported a history of migraines, and one patient was positive for the Human Immunodeficiency Virus. Three patients reported a surgical history, and one of these was a cesarean section. Two women were using depot medroxyprogesterone and 3 were taking oral contracep- tive pills. Three reported having taken antibiotics recently. Baseline data and comparison between the 2 groups is shown in Table 2 .

The chief complaint in 16 women (35\%) was itching, for $16(35 \%)$ it was odor, for $9(20 \%)$ it was discharge, and for $3(7 \%)$ it was irritation. One woman complained of severe vaginal burning, and one complained of vaginal erythema. Fourteen $(30 \%)$ of the women had taken some form of self-therapy (see Table 2).

Eleven providers participated in this study. Fortyone of the patients were managed by attending physicians; 5 were managed by residents under the direct supervision of attending physicians. Thirty patients $(65 \%)$ were evaluated by one provider.

\section{Management in Each Arm}

Twenty-two of the 46 women were randomized to the control group (see Table 3 and Figure 1). In the 
Table 3. Initial Management of Forty-six Women with Vaginal Symptoms

\begin{tabular}{lcc}
\hline & $\begin{array}{c}\text { Intervention Group } \\
(\mathrm{n}=24)\end{array}$ & $\begin{array}{c}\text { Control Group } \\
(\mathrm{n}=22)\end{array}$ \\
\hline Bacterial vaginosis & 9 & 1 \\
Empiric & 0 & 9 \\
Confirmed & & 3 \\
Candidal vaginitis & 14 & 8 \\
Empiric & 0 & 0 \\
Confirmed & 1 & 1 \\
Both bacterial vaginosis & & \\
and candida & 0 & 3 \\
No treatment given & & \\
\hline
\end{tabular}

control group, 10 women were treated for bacterial vaginosis: 9 based on the Amsel criteria ${ }^{18}$ and 1 empirically. Eleven were treated for candida: 8 based on observed yeast forms and 3 empirically. It was determined that one woman had normal discharge and was given no therapy. In the symptomatic treatment group (24 women), 14 (58\%) were treated for candida, 9 (38\%) for empiric bacterial vaginosis, and one for both.

\section{Symptomatic Results}

Two patients were lost to follow-up (one in each arm), so follow-up data were available for $44 \mathrm{pa}-$ tients (see Table 4). At the time of the follow-up phone call 41 (93\%) of the patients had improved. Three women were not improved (all from the control group). Thirteen women were somewhat better, 8 of whom were in the control group. Twenty-eight patients were completely improved, 10 of whom were in the control group. Among the 3 patients with an STD, one was completely better, one was somewhat better, and the third did not complete the follow-up interview; these women are included in the outcomes analysis. The symptom-based algorithm provided better relief at 2 weeks compared with the control group ( $P=.046$; Fisher's exact test).

We also evaluated symptom relief using the VSS, a 19-question scale with a maximum score of 41. Baseline VSSs were collected for 42 women and showed a mean value of 13.4 (SD, 6.6). Two-week follow-up VSSs (done for 44 women) had a mean value of 3.8 (SD, 5.7). Using the linear regression model, the change in score from baseline was statistically significant; differences in baseline VSS and changes in the VSS between the control and intervention groups were not statistically significant.

\section{Adverse Outcomes and Satisfaction with Visit}

Two women came in for revisits for vaginal symptoms within 2 weeks of enrollment. One was in the intervention group; the other in the control group.

Adverse reactions were measured by 4 questions, which assessed nausea, stomach discomfort or pain, headache, and fever/chills on a 4-point scale (none, slight amount, moderate amount, a lot). The maximum score was 12 . The mean value in the control group was 0.65 ; in the intervention group it was $0.43(P=.57 ; t$ test $)$.

Satisfaction with care was measured by 5 questions that assessed time spent with the doctor, quality of explanation, physician skills, physician's personal manner, and overall impression of the visit. Each variable was scaled on a point scale of 0 to 4 (poor, fair, good, very good, excellent), with a maximum of 20 points. The mean value in the control group was 17.6; in the intervention group it was $18.6(P=.29 ; t$ test $)$.

\section{Screening for STDs}

Forty-two women were tested for gonorrhea and chlamydia; one woman (2.4\%), aged 24 , tested positive for both conditions and was treated. Two women (5\%), aged 29 and 37, of the 42 women tested for trichomonas had positive cultures and were also treated. In summary, 3 (7\%) of 42 women tested had STDs. Two of these women denied a history of STD. One reported not being sexually active.

\section{Sample Size}

One goal of our pilot study was to estimate the sample size needed for a subsequent clinical equivalence trial. Clinical improvement in the intervention group was $100 \%$ (95\% CI, 80-100) and in the control group was $89.5 \%$ (95\% CI, 67-98). We assumed a $95 \%$ improvement in the control group and considered that a $10 \%$ deviation from this (ie, clinical improvement of only $85 \%$ ) was clinically significant. We calculated that a sample size of 60 patients in each arm would have an $80 \%$ chance of measuring this difference with a level of $0.05 \%$ significance.

\section{Discussion}

Our preliminary study suggested that, for selected patients presenting with vaginal symptoms, initial treatment based on symptoms may be a reasonable 


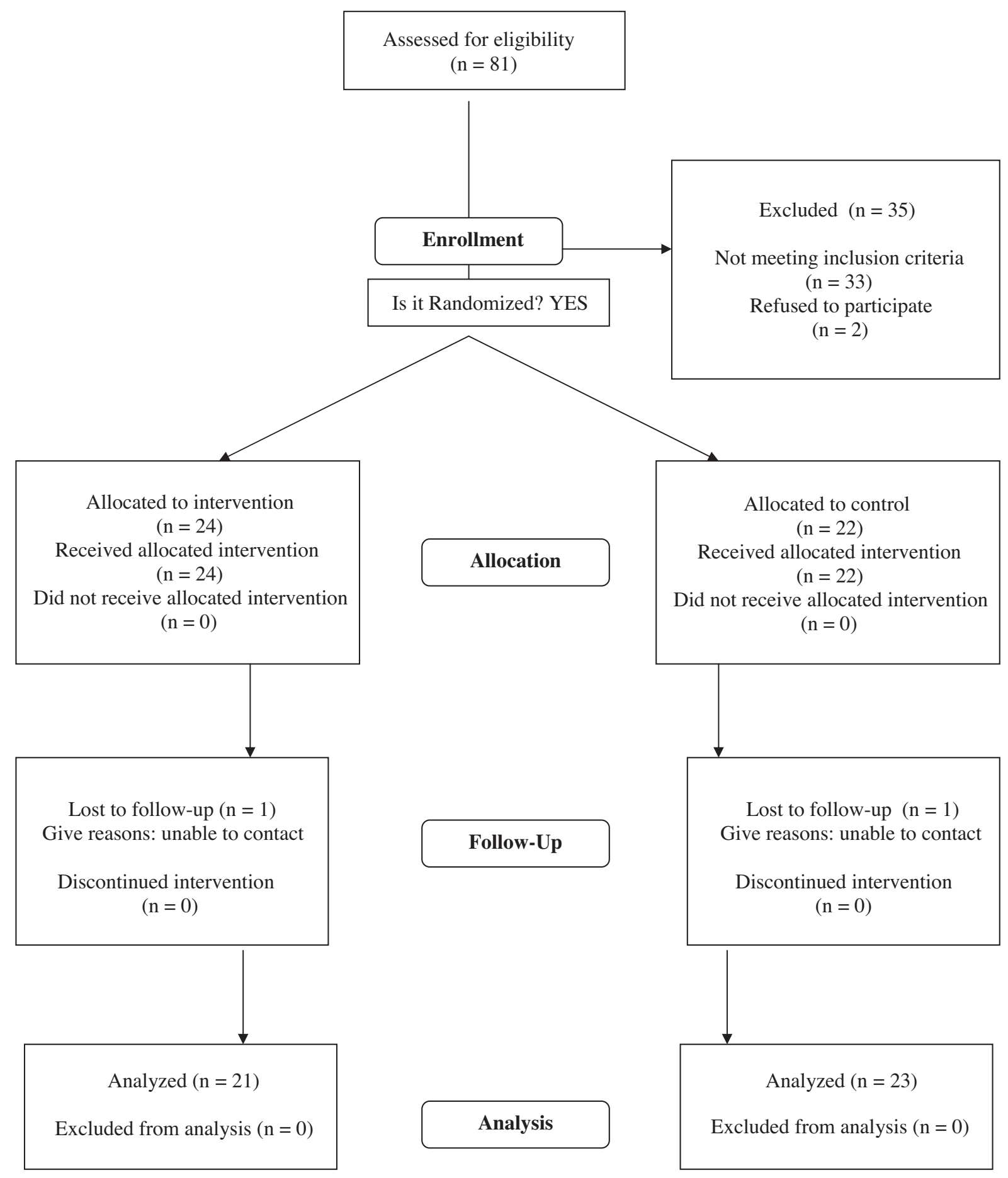

Figure 1. Flow chart of participant enrollment, randomization, follow-up and analysis (based on the CONSORT Flow Diagram: http://www.consort-statement.org/consort-statement/flow-diagram/).

option. Our symptomatic protocol was accepted by both patients and physicians. It resulted in equivalent clinical outcomes, patient satisfaction, and reports of adverse reactions. That $7 \%$ of patients had an STD suggests that testing for STDs is important in women with vaginal symptoms. Finally, 3 of the women in our study had no relief of symptoms at 2 weeks, indicating a failure of initial management.

This study did not have enough statistical power to answer our study hypothesis; it did, however, provide an estimate of the necessary study size (approximately 120 patients). Our conclusions were 


\begin{tabular}{lccc}
\hline & No Better & Somewhat Better & Completely Better \\
\hline All women & 3 & 13 & 28 \\
Control group & & & 0 \\
$\quad$ No diagnosis & 1 & 0 & 4 \\
$\quad$ Confirmed Candida & 2 & 2 & 6 \\
$\quad$ Confirmed bacterial vaginosis & 0 & 2 & 0 \\
$\quad$ Empiric Candida & 0 & 3 & 0 \\
Empiric bacterial vaginosis & 0 & 1 & 7 \\
Intervention group & & & 10 \\
$\quad$ Empiric bacterial vaginosis & & 2 & 1 \\
Empiric Candida & 0 & 3 & 0 \\
$\quad$ Both empiric bacterial vaginosis and empiric Candida & 0 & 0 & 1 \\
Women with STD & 0 & & \\
Trichomonas & & 1 & \\
$\quad$ GC and Chlamydia & 0 & 0 & \\
\hline
\end{tabular}

All data provided as $\mathrm{n}$.

*Two women were lost to follow-up. One of these had trichomonas.

${ }^{\dagger}$ Women in the ntervention group showed superior resolution of symptoms $(P=.046$; Fischer's exact test).

STD, sexually transmitted disease; GC, Gonorrhea.

also limited by the constraints imposed by a small pilot study. Sixty percent of patients were examined by one provider. The majority of the follow-up calls were made by an individual not blinded to treatment group. Four women had incomplete STD testing and 5 had an incomplete baseline VSS. We did not test for a microbiologic "cure," reflecting our view that the goal of treatment is the resolution of symptoms and not the eradication of microbes; others might disagree. Finally, we chose to follow-up women at 2 weeks' time. This may not be the appropriate time frame within which to assess symptom relief. Further study is needed to assess the time course for resolution (or nonresolution) of vaginal symptoms.

Our findings add to the literature suggesting that the "classic approach" to vaginal symptoms is due for an overhaul. ${ }^{19}$ A number of studies have either questioned the role of infectious agents in chronic vaginal symptoms ${ }^{20}$ or pointed to the importance of psychosocial factors in the etiology of vaginal symptoms. ${ }^{21-23}$ Researchers in the field are exploring protocols based on $\mathrm{pH}$ testing, ${ }^{17,24}$ selfcollection of samples, ${ }^{25}$ and more accurate tests such as polymerase chain reactions. ${ }^{26}$ It is also possible that vaginal symptoms often represent selflimited conditions. The task of the clinician may thus be to identify those patients with more serious or chronic conditions for whom further examination is indicated. Patients may also be better served by a fuller exploration of their social concerns related to vaginal symptoms. Finally, both patients and clinicians would benefit from a better understanding of vaginal physiology and what constitutes a meaningful departure from the "normal." 27

Dr. Clyde Schechter suggested the initial study design and provided valuable statistical consultation.

\section{References}

1. Kent HL. Epidemiology of vaginitis. Am J Obstet Gynecol 1991;165(4 Pt 2):1168-76.

2. Lipsky MS, Waters T, Sharp LK. Impact of vaginal antifungal products on utilization of health care services: evidence from physician visits. J Am Board Fam Pract 2000;13:178-82.

3. Eckert LO. Clinical practice. Acute vulvovaginitis. N Engl J Med 2006;355:1244-252.

4. ACOG Committee on Practice Bulletins-Gynecology. ACOG Practice Bulletin. Clinical management guidelines for obstetrician-gynecologists, Number 72, May 2006: Vaginitis. Obstet Gynecol 2006;107: 1195-206.

5. Workowski KA, Berman SM. Sexually transmitted diseases treatment guidelines, 2006. MMWR Recomm Rep 2006;55(RR-11):1-94.

6. Schaaf VM, Perez-Stable EJ, Borchardt K. The limited value of symptoms and signs in the diagnosis of vaginal infections. Arch Intern Med 1990;150:192933.

7. Berg AO, Heidrich FE, Fihn SD, et al. Establishing the cause of genitourinary symptoms in women in a 
family practice. Comparison of clinical examination and comprehensive microbiology. JAMA 1984;251: 620-5.

8. Mayaud P, ka-Gina G, Cornelissen J, et al. Validation of a WHO algorithm with risk assessment for the clinical management of vaginal discharge in Mwanza, Tanzania. Sex Transm Infect 1998;74(Suppl 1):S7784.

9. Bergman JJ, Berg AO. How useful are symptoms in the diagnosis of Candida vaginitis? J Fam Pract 1983; 16:509-11.

10. Blake DR, Duggan A, Joffe A. Use of spun urine to enhance detection of Trichomonas vaginalis in adolescent women. Arch Pediatr Adolesc Med 1999;12: 1222-5.

11. Anderson MR, Klink K, Cohrssen A. Evaluation of vaginal complaints. JAMA 2004;291:1368-79.

12. Anderson MR, Karasz A. How do clinicians manage vaginal complaints? An Internet survey. Med Gen Med 2005;7:61.

13. Wiesenfeld HC, Macio I. The infrequent use of office-based diagnostic tests for vaginitis. Am J Obstet Gynecol 1999;181:39-41.

14. Allen-Davis JT, Beck A, Parker R, Ellis JL, Polley D. Assessment of vulvovaginal complaints: accuracy of telephone triage and in-office diagnosis. Obstet Gynecol 2002;99:18-22.

15. Chandeying V, Skov S, Kemapunmanus M, Law M, Geater A, Rowe P. Evaluation of two clinical protocols for the management of women with vaginal discharge in southern Thailand. Sex Transm Infect 1998;74:194-201.

16. Ryan CA, Courtois BN, Hawes SE, Stevens CE, Eschenbach DA, Holmes KK. Risk assessment, symptoms, and signs as predictors of vulvovaginal and cervical infections in an urban US STD clinic: implications for use of STD algorithms. Sex Transm Infect 1998;74(Suppl 1):S59-76.

17. Nyirjesy P, Sobel JD. Advances in diagnosing vagi- nitis: development of a new algorithm. Curr Infect Dis Rep 2005;7:458-62.

18. Amsel R, Totten PA, Spiegel CA, Chen KC, Eschenbach D, Holmes KK. Nonspecific vaginitis. Diagnostic criteria and microbial and epidemiologic associations. Am J Med 1983;74:14-22.

19. Bornstein J, Lakovsky Y, Lavi I, Bar-Am A, Abramovici H. The classic approach to diagnosis of vulvovaginitis: a critical analysis. Infect Dis Obstet Gynecol 2001;9:105-11.

20. Nyirjesy P, Peyton C, Weitz MV, Mathew L, Culhane JF. Causes of chronic vaginitis: analysis of a prospective database of affected women. Obstet Gynecol 2006;108:1185-91.

21. Karasz A, Anderson M. The vaginitis monologues: women's experiences of vaginal complaints in a primary care setting. Soc Sci Med 2003;56:1013-21.

22. Patel V, Pednekar S, Weiss H, et al. Why do women complain of vaginal discharge? A population survey of infectious and pyschosocial risk factors in a South Asian community. Int J Epidemiol 2005;34:853-62.

23. Nansel TR, Riggs MA, Yu KF, Andrews WW, Schwebke JR, Klebanoff MA. The association of psychosocial stress and bacterial vaginosis in a longitudinal cohort. Am J Obstet Gynecol 2006;194: 381-6.

24. Kulp JL, Chaudhry S, Wiita B, Bachmann G. The accuracy of women performing vaginal $\mathrm{pH}$ self-testing. J Womens Health (Larchmt) 2008;17:523-6.

25. Mabey D, Ackers J, Adu-Sarkodie Y. Trichomonas vaginalis infection. Sex Transm Infect 2006;82(Suppl 4):iv26-7.

26. Mayta H, Gilman RH, Calderon MM, et al. $18 \mathrm{~S}$ ribosomal DNA-based PCR for diagnosis of Trichomonas vaginalis. J Clin Microbiol 2000;38: 2683-7.

27. Anderson MR, Karasz A, Friedland S. Are vaginal symptoms ever normal? A review of the literature. MedGenMed 2004;6:49. 